\title{
Social justice representations of students and teachers in Spain
}

\author{
Vanesa Sainz $^{1 \mathrm{a}}$, Almudena Juanes ${ }^{1}$, Tatiana García-Vélez ${ }^{1}$, Liliana Jacotta ${ }^{1}$ and Antonio \\ Maldonadoa ${ }^{1}$ \\ ${ }^{1}$ Universidad Autónoma de Madrid, Ciudad Universitaria de Cantoblanco, Madrid, 28049, Spain
}

\begin{abstract}
In this empirical study, we designed a questionnaire that seeks to analyse the representation that Spanish students and teachers have about Social Justice. The questionnaire includes a set of different dilemmas about social justice issues, especially in educational context The questions equitably represent three fundamental dimensions in social justice: Representation, Redistribution and Recognition. The questionnaire for students has 30 dilemmas and for teachers has 39 ones. The instrument has been applied to a sample of teachers and students of secondary education in 17 secondary public schools of different Spanish Communities Autonomous. The results show a good reliability of our instrument and differences in social justice conceptions regarding level of education, age and gender. These results show a developmental and gender trend and differences between students and teachers in the accessibility to the three dimensions of Social Justice: Representation, Recognition and Representation.
\end{abstract}

Keywords. Social justice; redistribution; recognition; representation; education; students; teachers.

\section{Introduction}

Nowadays, Social Justice concept is being analyzed deeply. A large number of important issues about Social Justice has being proposed and discussed from different views and there is not an univocal concept about it. As we live in a changing society, Social Justice is a dynamic concept and it always should be thought over and to be improved.

In this research, we have assumed social justice concept based on proposal of Sen [11] about redistribution of capabilities and ideas of Fraser [4, 5] about recognition and representation as complementary elements:

\footnotetext{
${ }^{a}$ Corresponding author: vanesa.sainz@uam.es
} 
-Redistribution of material and cultural resources and of primary goods Rawls, 1971; $11]$.

- Recognition and celebration of diversity through the individual, cultural and social appraisement of all people in a just relationship [5,14].

- Representation or active participation of people in important decisions that concert their own lives, especially belonging to traditionally excluded collectives. [5]

We consider that these three dimensions form the means for active promotion of Social Justice. For these reasons, we are going to focus in Social Justice about Redistribution, Recognition and Representation dimensions. These concepts are highly related and share common aspects.

Furthermore, it is important to know what we want to achieve through Social Justice. From our perspective, Social Justice should reach the following goals:

- In the first place, achieving human dignity through development of capabilities and overcoming inequalities following the proposal of Nussbaum [8] and Sen [11]. By means of development of human capabilities, we achieve a dignified and full life of all human beings.

- The second important goal is obtaining individual and collective welfare. Following the ideas of Prillentensky [9], welfare could reach through mutual assistance, cooperation and participation of all people in a fair democracy.

- Thirdly, based on Westheimer and Kahne [13] we consider another goal of Social Justice is becoming in Social Justice oriented citizens. They are autonomous, active and critical people with social, political and economic structures that promote inequalities and unfair so they act as change agents.

In this sense, we consider the most important mission of education is to form students to be able to denounce and intervene in unfair situations becoming in committed citizens to achieving fair and democratic society.

Otherwise, social justice representations of students and teachers are elements that will have an effect in their actions (or inactions) of their own schools. There are several studies that prove it $[6 ; 2 ; 1 ; 3]$ but there are not so much quantitative studies about the concept that students and teachers have about Social Justice and their implications in schools. We consider that it is very important to know these representations of students and teachers to promote transformation in schools that work for social justice.

In this research, we focused on knowing and analyzing the social justice concept of secondary students and teachers in different regions of Spain. This study is part of national research project (EDU 2011-29114) called "Schools for social justice" funding by the Spanish government and conducted by research group GICE (http://www.gice-uam.es/) from Autonomous of Madrid University.

\subsection{Objectives}

In this research, we have assumed the following general objectives:

1. To design an instrument in order to know social justice representation of students and teachers in Spain.

2. To know and to analyze the representations of students and teachers about social justice, specially focusing on educational topics.

3. To compare social justice representations between students of different educational levels and teachers. 


\section{Method}

\subsection{Design and structure of instrument}

In order to know social justice representation of students and teacher, we have elaborated "Questionnaire of Social Justice Representations" by different experts in the fields of education, psychology, history, linguistics, pedagogy and anthropology.

The questionnaire includes set of different questions with formulation of dilemmas about hypothetical situations or problems relating to social justice dimensions. These dilemmas are about different current issues, especially in educational context. Each dilemma has three alternatives or possible responses. One alterative is highly promoting of social justice, another alternative is opposite social justice and a third response that is more neutral or less promoting of social justice. Is important to note that in the social justice questionnaire, there are an equal number of dilemmas related to the three dimensions (Redistribution, Recognition and Representation).

To show more clearly the structure of questions, we present an example of the dilemmas:

Andrea is 8 years old and always goes to school in a wheelchair. The playground is a sandy area, and her family has requested that a part of this should be paved with a flat and firm surface to make it easier for her to go outdoor and play with the other children. This work is expensive. Which option would you support?

A) Spend whatever is necessary and begin the works as soon as possible, so that Andrea can go out and play just like the others.

B) Fix at least half of the playground so that she can go out and play.

C) Spend more on improvements that will benefit the majority, and seek an alternative solution for individual cases such as this.

This dilemma is about redistribution dimension and in this case, the A alternative is highly promoting of social justice, the B alternative is more neutral or less promoting of social justice and the last one is opposite social justice.

Social Justice Questionnaire for students has 30 dilemmas (10 in each dimension) and questionnaire for teachers has 39 ones (13 in each dimension) and it includes the 30 questions of students' questionnaire. This allow making comparison among answers of students and teachers.

The questionnaire has been subject to a double process of validation. On the one hand, validation of experts who have validated each one of the three alternatives in a likert scale of social justice from 1 to 9 . On the other hand, a pilot study with a sample of training teachers. After this double process, we achieve the final version of our instrument.

Finally, using this questionnaire we have obtained a global index of social justice (Total Social Justice Scale) and three specific indexes of the three main dimensions of social justice (Redistribution Scale, Recognition Scale, Representation Scale). These indexes have been adapted to a range from 1 to 100 .

\subsection{Participants}

The questionnaire has been applied to a sample of 2763 students and 158 teachers belonging to 17 high public schools of different communities autonomous of Spain (Madrid, Castila and Leon, Extremadura and Andalusia). Regarding distribution of sample by gender, 1525 women and 1401 men have participated. You can see the exact distribution by grade and gender in the tables 1 and 2 . 
Table 1. Distribution of students by grade and gender

\begin{tabular}{cccc}
\hline Grade & Frequency & Gender & Frequency \\
\hline $\begin{array}{l}\text { 2nd Secondary } \\
\text { (14 years old) }\end{array}$ & $1010(36,6 \%)$ & Men & $1330(47,9 \%)$ \\
$\begin{array}{l}\text { 4th Secondary } \\
(16 \text { years old })\end{array}$ & $872(31,6 \%)$ & & \\
2nd & & Women & $1438(51,9 \%)$ \\
$\begin{array}{l}\text { Baccalaureate } \\
(18 \text { years old })\end{array}$ & $881(31,9 \%)$ & & \\
\hline TOTAL & $2763(100 \%)$ & & \\
\hline
\end{tabular}

Table 2. Distribution of teachers by gender

\begin{tabular}{ll}
\hline Gender & Frequency \\
\hline Men & $72(44,3 \%)$ \\
Women & $87(55,1 \%)$ \\
\hline TOTAL & $158(100 \%)$ \\
\hline
\end{tabular}

\section{Results}

The Social Justice Questionnaire show a Cronbach's alpha coefficient of 0,74 showing an adequate internal consistence and reliability to evaluate the representation of students and teachers about social justice.

Regarding students, there is a clear developmental trend in all Social Justice Dimensions because when the educational level and age increase the results present high values in all indexes of social justice (Redistribution of resources and capabilities, Recognition and valuation of all people and Representation or democracy participation). These results show that the representation of social justice is developed along the life. Maybe they are influenced by the experiences of life and evolutionary development of being humans.

As you can see in the figure 1 , there are significant differences $(p<0.0001)$ among students of all grades (2nd of secondary, 4th of secondary, 2nd of baccalaureate) in the Redistribution dimension and Total social justice dimension. However, regarding recognition and representation dimensions, there are significant differences $(\mathrm{P}<0.0001)$ among students of 2 nd and 4th grade of secondary education.

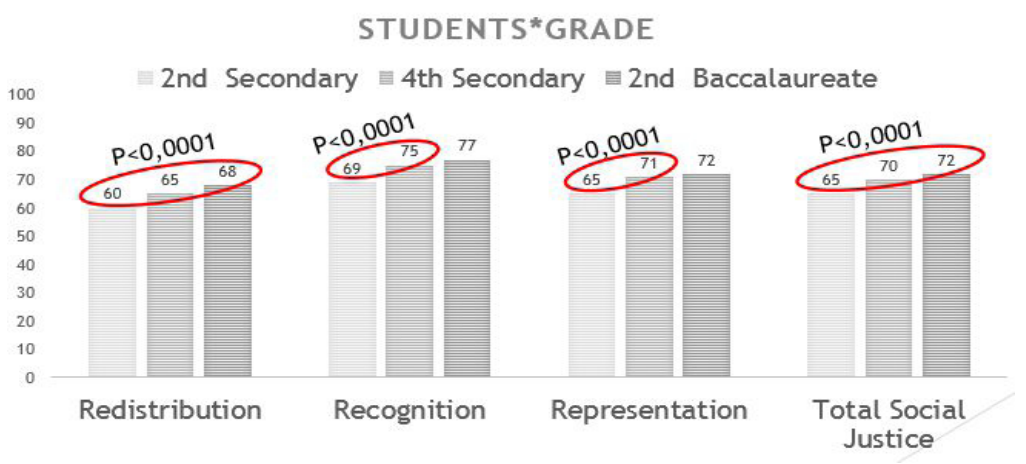

Fig 1. Differences of Social Justice dimension of students by grade 
Respecting differences of students and teachers, as figure 2 shows teachers present mean values significant higher than students do in all dimensions. Otherwise, it is important to highlight that for students is easier to think about social justice in terms of recognition of diversity, following of representation or participation and lastly in terms of redistribution of goods and capabilities. However, teachers propound social justice more in terms of Recognition and Redistribution.

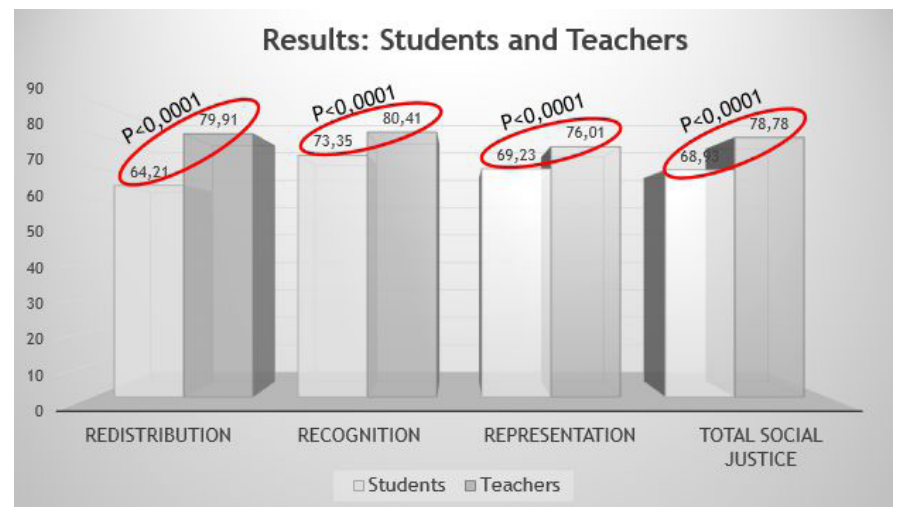

Fig 2. Differences between students and teachers

Regarding the differences between men and women, results show that in general women have more elaborated conception of social justice dimensions than men do. However, the differences by gender are bigger in students than in teachers and we found significant differences in recognition, representation and total social justice scales in students but there aren't significant differences in teachers. These results show that the differences by gender decrease with age and educational level increase so representations of social justice tend to be closer between women and men for older people.
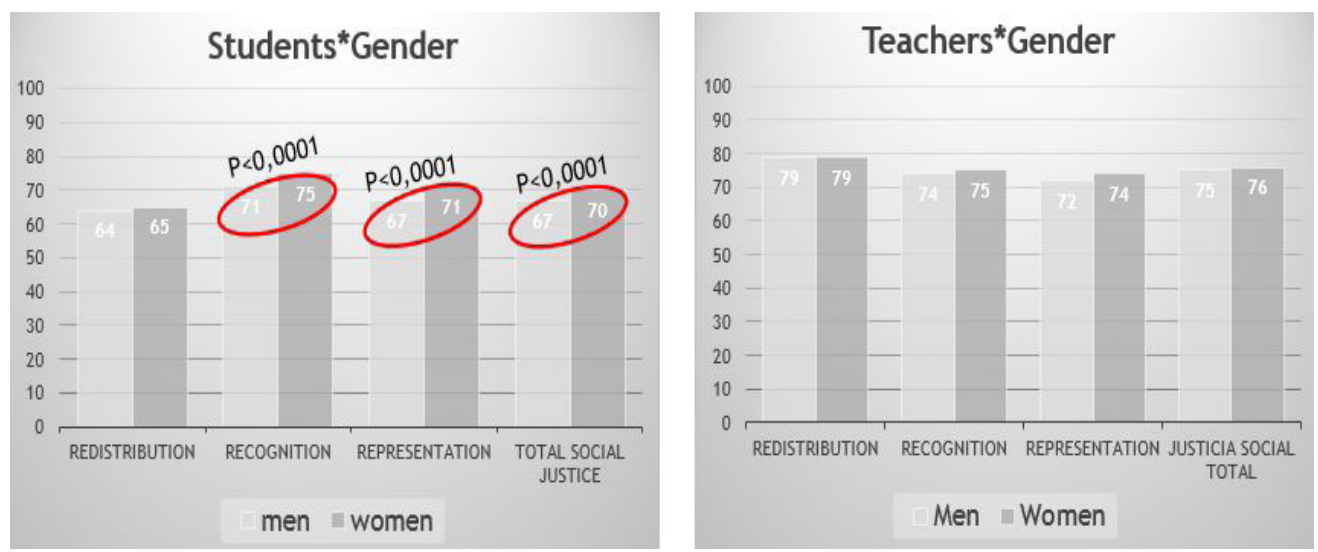

Fig 3. Differences of students and teachers by gender 


\section{Conclusions}

Our pilot questionnaire has a high reliability so we have designed a good instrument to evaluate social justice representations of students and teachers. We have obtained a developmental trend because the results show higher values in Social Justice Scales when students and teachers have more level of education and age. Regarding differences by gender, in all age groups, women have obtained higher mean values than men do, but these differences decrease in older groups. Besides, we have found differences in the relevance of three dimensions between students and teachers. t present, we are doing focus groups about some dilemmas of our questionnaire in order to advance in qualitative analysis and do a deeper analysis in the most controversial dilemmas.

\section{References}

1. Applebaum, B. Social justice education, moral agency, and the subject of resistance, Educational Theory, 54 (1) 59-72, (2004).

2. Baldwin, S. C., Buchanan, A. M., \& Rudisill, M. E. What teacher candidates learned about diversity, social justice, and themselves from service-learning experiences. Journal of Teacher Education, 58(4), 315-327, (2007).

3. Cochran-Smith, M. The new teacher education: for better or for worse? Educational Researcher, 34(6), 181-206, (2005).

4. Fraser, N. Honneth, A. Redistribution or recognition? A political-philosophical exchange. Londres: Verso Press, (2003).

5. Fraser, N. Scales of justice: Reimagining political space in a globalizing world. Columbia University Press, (2009).

6. McDonald, M. The integration of social justice in teacher education. Journal of Teacher Education, 56(5), 418-435, (2005).

7. Nussbaum, M. Women and human development: the capabilities approach. Cambridge, UK: Cambridge University Press, (2000).

8. Nussbaum, M. C. Creating capabilities. Harvard University Press, (2011).

9. Prilleltensky, I. Wellness as fairness. American Journal of Community Psychology, 49(1-2), 1-21, (2012).

10. Rawls, J. A theory of justice. Oxford University Press. New York, (1971).

11. Sen, A. Gender inequality and theories of justice. In M. Nussbaum and J. Glover (eds.) Women, Culture and Development, pp. 259 - 73. Oxford: Clarendon Press, (1995).

12. Sen, A. The Idea of Justice. Cambridge: Harvard University Press, (2009).

13. Westheimer, J., \& Kahne, J. What kind of citizen? The politics of educating for democracy. American educational research journal, 41(2), 237-269, (2004).

14. Young, I. M. Justice and the politics of difference. Princeton University Press, (2011).

15. Young, I. M., \& Nussbaum, M. Responsibility for justice. Oxford University Press, (2013). 